\title{
Orexin A Expression and Promoter Methylation in Patients with Cannabis Dependence in Comparison to Nicotine-Dependent Cigarette Smokers and Nonsmokers
}

\author{
Andrea Rotter Kristina Bayerlein Max Hansbauer Judith Weiland \\ Wolfgang Sperling Johannes Kornhuber Teresa Biermann \\ Department of Psychiatry and Psychotherapy, Friedrich Alexander University, Erlangen-Nuremberg, Germany
}

\author{
Key Words \\ Orexin A - mRNA • Promoter methylation • \\ Tetrahydrocannabinol $\cdot$ Cannabis dependence $\cdot$ Nicotine \\ dependence $\cdot$ Treatment $\cdot$ Naturalistic study
}

\begin{abstract}
Background: The orexins (hypocretins) are neuropeptides with an origin in the lateral hypothalamus. They have been found to be crucial within the context of drug craving, withdrawal und relapse. Methods: Therefore, orexin A gene expression and promoter methylation in peripheral blood cells of 77 subjects [ 36 with tetrahydrocannabinol (THC) dependence, 20 nicotine-dependent cigarette smokers and 21 nonsmokers] were assessed by quantitative real-time PCR and methylation-specific digestion PCR. Results: There was a statistically significant difference in orexin $A$ expression between the three groups $[p=0.000, F=131.4$, d.f. $=2$, analysis of variance (ANOVA)]. Orexin A gene expression was statistically significantly correlated with the Satisfaction with Life Scale $(r=-0.28, p=0.018)$, a visual analogue scale of craving $(r=0.734, p=0.000)$ and three subscales of the World Health Organization Alcohol, Smoking and Substance Involvement Screening Test, i.e. nicotine consumption ( $r=$ $0.388, p=0.001)$, alcohol consumption $(r=0.354, p=0.002)$ and cannabis consumption $(r=0.783, p=0.000)$. The mean promoter methylation (as a percentage) was not statistically
\end{abstract}

related to orexin gene expression. However, there was a statistically significant difference in promoter methylation with regard to body mass index in general $(F=2.37$, d.f. $=54, p=$ 0.016 , ANOVA). Conclusions: Orexin might be a possible target in THC as well as nicotine dependence, taking into account the effect of THC on energy homeostasis in the circuit of reward and motivation and its impact on appetite and body weight.

Copyright $\odot 2012$ S. Karger AG, Basel

\section{Introduction}

Psychoactive preparations of Cannabis sativa have been used for medical or religious purposes for over 4,000 years [1]. Cannabis is able to produce mild euphoria, relaxation and perceptual alterations including a disruption of time experience and memory as well as intensification of sensory impressions accompanied by increased sociability [2]. Marijuana is the most commonly used illegal drug worldwide. Since the 1990s, rates of cannabis abuse and even dependence have risen considerably [3]. The majority (90\%) of cannabis users who seek treatment to achieve abstinence do not succeed in maintaining abstinence due to unspecific withdrawal symptoms such as irritability, anxiety, marijuana craving and disrupted sleep $[4,5]$. 
Nicotine dependence in the form of tobacco use is a worldwide phenomenon with captivating influence and massive associated health consequences as well as addictive properties; the majority of cigarette smokers do not succeed in sustaining abstinence due to similar mechanisms as described above [6].

Recently, the cannabinoid receptors $\mathrm{CB} 1$ and $\mathrm{CB} 2$ and the existence of endocannabinoids such as anandamide have been discovered, resulting in an increased interest in the neurobiological effects of chronic cannabis abuse or dependence $[7,8]$. Endocannabinoids are hydrophobic lipid messengers derived from integral components of the phospholipid layers of various cells; these neurotransmitter-like endocannabinoids are produced 'on demand' and activate cannabinoid receptors locally or at least nearby [9]. $\mathrm{CB} 1$ and $\mathrm{CB} 2$ are $\mathrm{G}$ protein-coupled receptors; $\mathrm{CB} 1$ is primarily expressed in the brain whereas $\mathrm{CB} 2$ is predominantly found on the cells of the immune system [10].

The appetite-stimulating effects of the products of $C$. sativa have been known for a long time, as cannabinoids have been used to abolish loss of appetite and diminish pain and nausea [11]. It has been described that cannabinoids as well as endocannabinoids that act on brain CB1 receptors stimulate appetite and ingestive behaviors at least in part through associations with orexigenic signals [12]. Orexin A seems to play a distinct role in energy homeostasis, regulation of appetite and food consumption, reward and alcohol addiction and withdrawal, gastric secretion, arousal and stress processing and the sleep-wake cycle $[13,14]$. Recent research has been able to demonstrate that cannabinoids and orexin have common mechanisms of action, in that hypothalamic orexigenic circuits are involved in reduction of appetite via CB1 receptor antagonism (Rimonabant) followed by weight loss [12]. Cannabinoid receptors have been found to interact with neuropeptide circuits involved in feeding regulation, including the orexins [12]. Biochemical, pharmacological and functional evidence hints at a cross-talk between CB1 and orexin receptors [15]. Orexin deficiency as observed in narcolepsy causes abnormalities in energy homeostasis and reward systems $[16,17]$. Nicotine has also been found to interact with the orexin system; a study on human cigarette smokers has demonstrated a negative correlation between orexin plasma concentration and nicotine craving [18].

Furthermore, an endocannabinoid site of action causing hedonia has been found in the medial shell of the nucleus accumbens [19]. Orexin neurones originate from the lateral hypothalamus, which projects orexin to the nucleus accumbens, as well as the ventral pallidum as the direct recipient of the nucleus accumbens [20]. Hypotha- lamic orexigenic circuits are correlated with CB1 receptor function in food intake reward processing and reinforcement learning [12].

In support of the idea that orexin and cannabinoids are involved in reward mechanisms, both agents have been shown to directly affect mesolimbic reward pathways $[21,22]$. Considering their influence on dopaminergic transmission and reward processing during feeding, orexin neurones also seem to be implemented in addictive disorders [23].

Therefore, cannabis consumption leading to activation of $\mathrm{CB} 1$ receptors [7] and orexin may interact with each other during pleasure generation, e.g. upon tetrahydrocannabinol (THC) consumption in the brain.

Furthermore, orexin signalling seems to play a critical role in nicotine addiction and withdrawal, as has been shown in animal research [24].

Nevertheless, addiction is a disease of an individual person who is prone to become addicted to a certain substance such as cannabis or nicotine due to a variety of causes [25]; among others, the development of dependence upon cannabis consumption seems to be caused by many different genes, with a rather moderate effect of each specific gene [26]. It is not known if THC has an influence on the regulation of epigenetic phenomena such as histone modulation or promoter DNA methylation of specific genes [27], but it has been shown that cigarette smoking is capable of influencing these epigenetic phenomena in various ways [28].

Thus, the aim of the present pilot study was to inquire into the possibility of reflecting changes in orexin RNA expression and promoter methylation using a digestion assay-based PCR in peripheral blood lymphocytes comparing THC-dependent subjects with a sex- and agematched group comprising nicotine-dependent subjects and a control group of nonaddicted subjects and therefore nonsmokers in relation to several clinical variables such as sex, age, body mass index (BMI), craving, abuse of several other substances and satisfaction with life.

\section{Materials and Methods}

Patients and Study Design

The present study was approved by the Ethics Committee of the University of Erlangen-Nuremberg. In sum, 77 subjects were recruited for this study on a voluntary basis from acquaintances of students. The participants received an adequate amount of compensation money.

Thirty-six of those subjects suffered from THC dependence, and the remainder of the study group comprised 20 age- and sexmatched otherwise mentally and physically healthy cigarette 
smokers as well as 21 non- and never-smokers. Cigarette smokers did not suffer from any relevant somatic or mental diseases except for their nicotine dependence as assessed by the Symptom Checklist-90-Revised and a physical examination.

Inclusion criteria were cannabis as well as nicotine dependence as assessed by the authors before enrolment into the study, and exclusion criteria were other mental or physical diseases at the time of assessment. Participation was voluntary and could be withdrawn any time.

The 36 THC-dependent subjects had an established diagnosis of THC dependence according to DSM-IV and ICD-10 criteria and signed an informed consent form before participating in any part of the study. Most of them chose to stay anonymous so that data protection was also adequate; the data of those who did not stay anonymous were processed according to the Laws of Data Protection of German Law.

Orexin expression and promoter methylation in peripheral blood lymphocytes was measured in the evenings at $17.00 \mathrm{~h}$ to avoid bias due to differences caused by circadian variations.

The mean age in the group of THC-dependent subjects was 31.58 years, with a standard deviation (SD) of 7.1. This group comprised 28 males $(77.8 \%)$ and 8 females $(22.2 \%)$ with a mean BMI (BMI = weight in kilograms/square of height in centimeters) of 23.9 (SD 3.2), taking into account both sexes. Cannabis was consumed in every possible way on a daily basis.

The mean age in the group of cigarette-smoking persons was 33.3 years (SD 8.8); $70 \%$ of them were male and their mean BMI was 25.6 (SD 2.9). Cigarette smokers consumed a mean of 17.8 cigarettes/day (range 5-35 cigarettes per day, SD 6). The last cigarette before blood was drawn and craving was assessed was smoked $1 \mathrm{~h}$ before the procedures.

Nonsmoking subjects had a mean age of 30.9 years (SD 8.7); $71.4 \%$ were male and they had a mean BMI of 24.8 (SD 4.2). There were no statistically relevant differences between the three groups.

All of the participants were otherwise physically and mentally healthy as assessed with the Symptom Checklist-90-Revised [29] and a brief physical examination. Furthermore, several clinical scales were applied. The Satisfaction with Life Scale (SWLS) was employed to measure satisfaction with life [30]; it comprises 5 items that can be answered with a 1-7 Likert scale. Then, a sum score is calculated ranging from 0 to 35 points and used for further analysis. Craving was assessed with a visual analogue scale, and the World Health Organization (WHO) Alcohol, Smoking and Substance Involvement Screening Test (ASSIST) version 3.0 was performed for the assessment of involvement with alcohol, nicotine and illegal substances [31].

Participants were sober at the time of enrolment into the study. They took no vitamin supplements or other drugs before being enrolled in the study. The subjects showed no nutritional abnormalities, liver cirrhosis, renal or pancreatic dysfunction or psychiatric comorbidities. The enrolled patients did not suffer from comorbid narcolepsy.

Study characteristics of the participants such as medical history, sociodemographic data, time of drug or alcohol consumption and clinical scales were obtained using a semistructured interview in accordance with former studies on alcoholism [32].

\section{Laboratory Analyses}

Fasting blood samples for RNA extraction were drawn at $17.00 \mathrm{~h} \pm 15 \mathrm{~min}$ in each case in Paxgene ${ }^{\mathrm{TM}}$ Blood RNA tubes
(PreAnalytiX GmbH, Hombrechtikon, Switzerland) and were stored at $-80^{\circ} \mathrm{C} 2 \mathrm{~h}$ after collection according to the manufacturer's instructions. Total RNA was extracted from whole frozen EDTA-blood using the Qiacube and the corresponding protocol (QIAGEN GmbH, Hilden, Germany). Reverse transcription was performed using the Bio-Rad Laboratories' iScript cDNA Synthesis Kit ${ }^{\circledR}$ (Bio-Rad Laboratories GmbH, Germany) after measuring RNA quality and quantity using Nanodrop as well as an Experion $^{\mathrm{TM}}$ Automated Electrophoresis System (Bio-Rad Laboratories). Quantitative PCR was performed using SYBR Green ${ }^{\circledR}$ Master Mix buffer (Applied Biosystems, Darmstadt, Germany), and reactions were run on a Light cycler (Roche ${ }^{\mathrm{TM}}$ ) using a 3-step standard protocol. The annealing temperature was optimized for the primer pair and was $61^{\circ} \mathrm{C}$. PCR products were visualized on standard $2.0 \%$ agarose gels with ethidium bromide. $\beta$-Actin was used as an internal standard, and the change in threshold cycle $(\Delta \mathrm{Ct})$ values were calculated from differences between $\beta$-actin and orexin. All experiments were repeated at least 3 times, and the mean value was used for further analysis.

The following primer pairs were used: $\beta$-actin forward, $5^{\prime}$ CTGGAACGGTGAAGGTGACA-3', $\beta$-actin reverse, $5^{\prime}$-AAGGGACTTCCTGTAACAATGCA-3'; orexin A forward, 5'-CCTTCCTGGCTGAAGTGAAG-3', orexin A reverse, 5' -AGTGGGAGAAGGTGAAGCAG-3'.

\section{Promoter Methylation Analysis of the Orexin A Promoter}

Analysis of orexin promoter DNA methylation was performed applying a methylation-sensitive digestion assay as previously described [33] followed by real-time PCR. Firstly, genomic DNA was extracted from whole tissue with the QIAamp ${ }^{\circledR}$ DNA Blood and Tissue Kit (QIAGEN Inc., Valencia, Calif., USA) according to the manufacturer's instructions. Afterwards, $0.5-1 \mathrm{mg}$ of genomic DNA was digested overnight with a 10 -fold excess of HpaII or MspI endonuclease according to the manufacturer's protocol (New England Biolabs, Beverly, Mass., USA). MspI cuts independently from methylation status at $5^{\prime}$-CCGG-3' sites, whereas cutting by HpaII depends on the respective DNA methylation status. In a $20-\mu$ l assay, altogether $40 \mathrm{U}$ of each restriction enzyme were used for $16 \mathrm{~h}$ with $20 \mathrm{U}$ initially and another $20 \mathrm{U}$ additionally after $4 \mathrm{~h}$ to complete DNA digestion.

To measure promoter methylation of the orexin A gene, quantitative PCR of the orexin A promoter was performed using a SYBR Green I Master Mix buffer (Applied Biosystems) with the primers orexin A forward (5'-TAAATTTACGGTGTTTGGTGGGTTC- $\left.3^{\prime}\right)$ and orexin A reverse (5'-ACCACGATAAAAAATAATAAACTCCGAT-3'), yielding a product of 212 base pairs.

To amplify the specific promoter region covering a CPG island of approximately $200 \mathrm{bp}, \mathrm{PCR}$ was performed as follows. PCR was carried out with a final volume of $25 \mu \mathrm{l}$, containing $1 \mu \mathrm{l}$ of each primer, $1 \mu$ l of digested template DNA and $12.5 \mu$ l of SYBR green ${ }^{\circledR}$ (Bio-Rad, Munich, Germany). The amplification was carried out with initial denaturing at $97^{\circ} \mathrm{C}$ for $10 \mathrm{~min}$, followed by 50 cycles of denaturing at $95^{\circ} \mathrm{C}$ for $2 \mathrm{~min}$, annealing for $90 \mathrm{~s}$ at $56^{\circ} \mathrm{C}$ and extension for $1 \mathrm{~min}$ at $72^{\circ} \mathrm{C}$. The product was visualized with a $2 \%$ agarose gel. All experiments were repeated 2 times.

Ct measurements were transformed using the formula

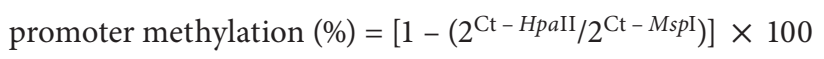

to calculate the percentage of methylation change. 


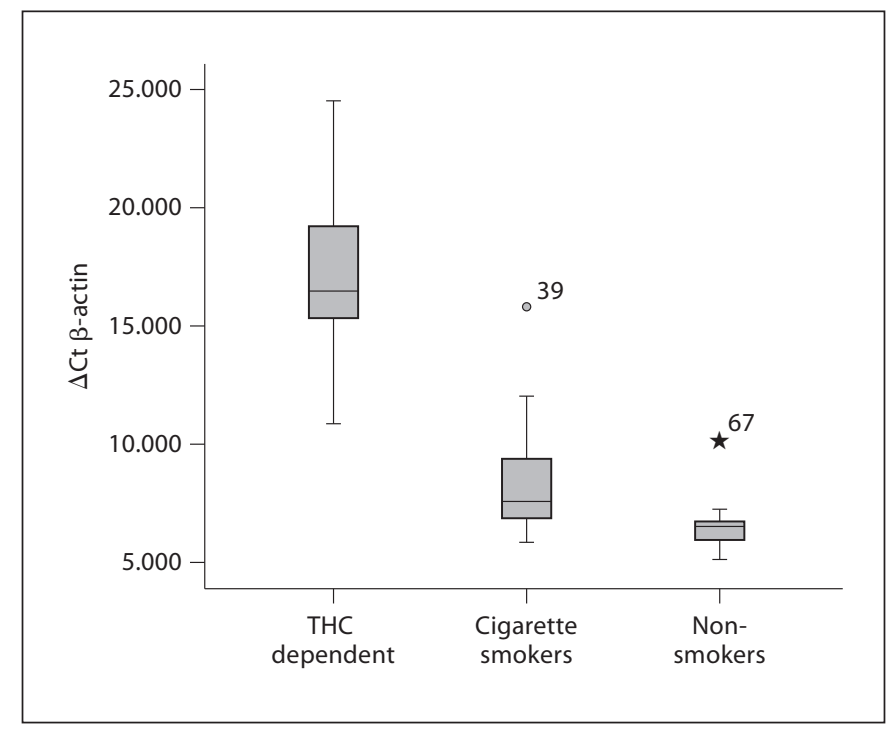

Fig. 1. Orexin A expression comparing THC-dependent subjects with smoking and nonsmoking controls. Shown are changes $(\Delta \mathrm{Ct}$ $\beta$-actin) in orexin mRNA expression in the three groups. Boxplots represent the raw data. The small circle represents cases with more than 1.5 box lengths from the upper or lower edge of the box; the box length is the interquartile range. The higher the $\Delta \mathrm{Ct}$ value, the lower the expression.

\section{Statistical Analyses}

Comparisons between groups were performed using either the Mann-Whitney U test or Kruskal-Wallis test, as most variables were not distributed equally. Wilcoxon and tests (where applicable) as well as analysis of variance (ANOVA) were used to test for marginal dependencies. Univariate analyses were applied to test for correlations between expression levels and promoter methylation taking into account sex, age, BMI and several clinical scales. A stepwise forward linear regression analysis was used to test for possible associations between different variables. A multivariate regression was used to test for possible associations between orexin mRNA and orexin promoter methylation.

All statistical tests were two-tailed, with a significance level of $\alpha=0.05$. Data were analyzed using SPSS ${ }^{\mathrm{TM}}$ for Windows 18.0 (SPSS Inc., Chicago, Ill., USA).

\section{Results}

The mean satisfaction with life was 21.7 points (SD 7.9) in the group of THC-dependent subjects, 29.2 (SD 4.1) in cigarette-smoking participants and 26.8 (SD 5.0) in nonsmoking participants. Mean craving for THC was 40.4 $\mathrm{mm}$ (SD 30.9) in the group of THC-dependent persons. Smokers as well as nonsmokers did not suffer from craving, even for cigarettes. Results of BMI, satisfaction with
Table 1. Results of BMI, satisfaction with life, THC craving, cigarette and alcohol consumption as well as the Fagerström test in the three study groups

\begin{tabular}{lccc}
\hline & $\begin{array}{l}\text { THC- } \\
\text { dependent } \\
\text { subjects }\end{array}$ & $\begin{array}{l}\text { Cigarette } \\
\text { smokers }\end{array}$ & $\begin{array}{l}\text { Non- } \\
\text { smokers }\end{array}$ \\
& 8 & 6 & 6 \\
\hline Females & 28 & 14 & 15 \\
Males & $23.9 \pm 3.2$ & $25.6 \pm 2.9$ & $24.8 \pm 4.2$ \\
BMI & $21.7 \pm 7.9$ & $29.2 \pm 4.1$ & $26.8 \pm 5.0$ \\
SWLS & $40.4 \pm 30.9$ & none & none \\
Craving VAS & $17.8 \pm 19.4$ & $13.75 \pm 6.0$ & 0 \\
Cigarettes per day & $13.2 \pm 6.3$ & $15.9 \pm 8.9$ & 0 \\
Duration of cigarette & $\quad$ smoking, years & & \\
$\quad$ Alcohol consumption & $\quad 3.58 \pm 7.54$ & $5.13 \pm 2.4$ & $5.6 \pm 3.3$ \\
$\quad$ units/week & $3.7 \pm 3.2$ & $3.0 \pm 1.9$ & 0 \\
Fagerström score & & & \\
\hline
\end{tabular}

Values represent numbers of patients or means $\pm \mathrm{SD}$, as appropriate. VAS $=$ Visual analogue scale.

life, craving and nicotine as well as alcohol consumption and results of the Fagerström test for nicotine addiction in the various groups are shown in table 1 .

There was a statistically significant difference in orexin expression between the three groups $(\mathrm{p}=0.000, \mathrm{~F}=$ 131.4, d.f. $=2$, ANOVA; fig. 1). Orexin expression was not influenced by sex, age or BMI (data not shown).

Craving measured with a visual analogue scale failed to reach a level of statistical significance but showed a trend towards an association with orexin mRNA expression $(\mathrm{p}=0.097, \mathrm{~F}=2.447$, ANOVA $)$

Orexin gene expression was statistically significantly correlated with the SWLS $(r=-0.28, p=0.018)$, the visual analogue scale of craving $(\mathrm{r}=0.734, \mathrm{p}=0.000)$ and three subscales of the WHO ASSIST, namely nicotine consumption $(\mathrm{r}=0.388, \mathrm{p}=0.001)$, alcohol consumption $(\mathrm{r}=0.354, \mathrm{p}=0.002)$ and cannabis consumption $(\mathrm{r}=$ $0.783, \mathrm{p}=0.000)$.

Promoter methylation did not differ between the three groups (fig. 2). The mean promoter methylation as a percentage was not statistically related to orexin gene expression. However, there was a statistically significant difference in promoter methylation with regard to $\mathrm{BMI}$ in general $(\mathrm{F}=2.37$, d.f. $=54, \mathrm{p}=0.016$, ANOVA; fig. 3$)$, which was even stronger when dichotomized at a BMI of 25 $(\mathrm{F}=12.9$, d.f. $=1, \mathrm{p}=0.001$, ANOVA; fig. 4).

Using a mixed general linear model to test for possible associations between orexin expression and promoter 


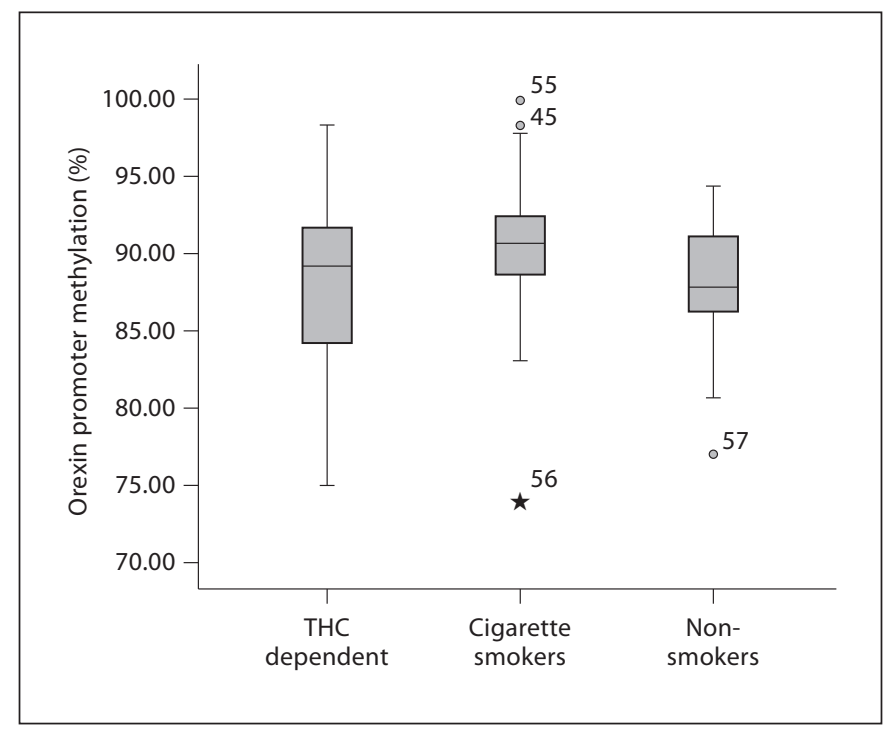

Fig. 2. Orexin A promoter methylation in the three groups. Boxplots represent the raw data. The small circles represent cases with more than 1.5 box lengths from the upper or lower edge of the box; the box length is the interquartile range.

methylation as well as several clinical variables (BMI, sex, age, WHO ASSIST nicotine, alcohol and cannabis subscales, SWLS and craving), we found that orexin gene expression was solely associated with the WHO cannabis subscale $(\mathrm{T}=7.106, \mathrm{p}=0.000)$ and craving $(\mathrm{T}=2.827$, $\mathrm{p}=0.006)$. Using the mean promoter methylation of the orexin gene as the dependent variable, promoter methylation was only related to the WHO cannabis subscale $(\mathrm{T}=-2.381, \mathrm{p}=0.02)$ and $\mathrm{BMI}(\mathrm{T}=2.083, \mathrm{p}=0.042)$.

\section{Discussion}

The presented results show that orexin expression is significantly altered, in the sense of downregulation, in patients with THC dependence compared to nicotine-dependent subjects and healthy controls. Cigarette smokers had lower orexin mRNA expression than nonsmoking healthy controls. Even though addiction is a disease of the individual subject, there might be a complex interplay between the addictive properties of the drug such as THC or nicotine and the individual predisposition, and the orexin system might play a part in the latter.

There are several lines of evidence that hint at a similar direction as the results from the presented studies. In animal studies, it has been found that Rimonabant, an in-

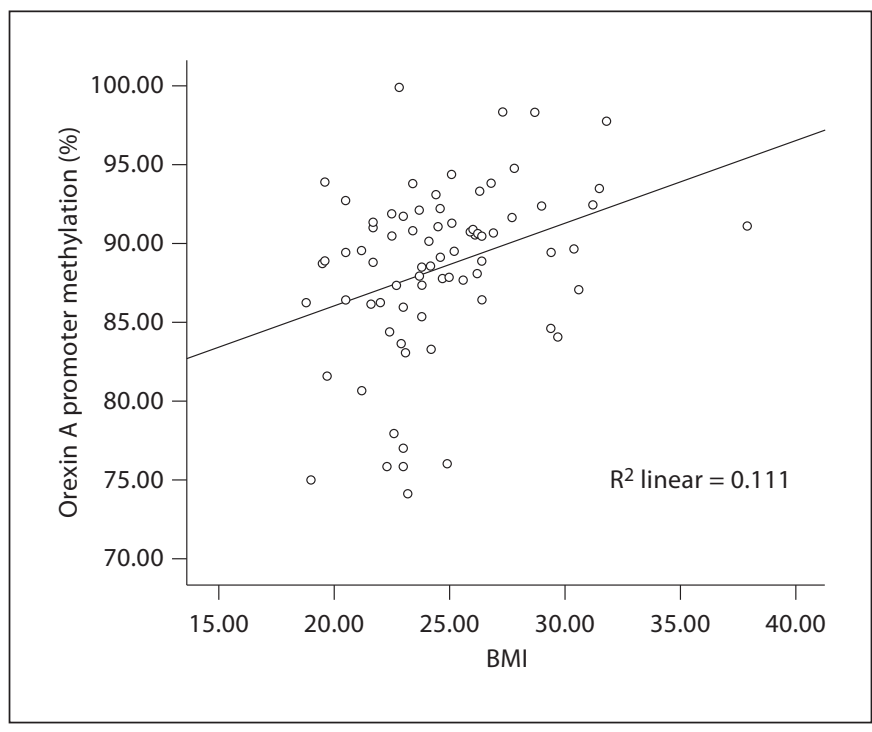

Fig. 3. Relation between BMI and orexin promoter methylation.

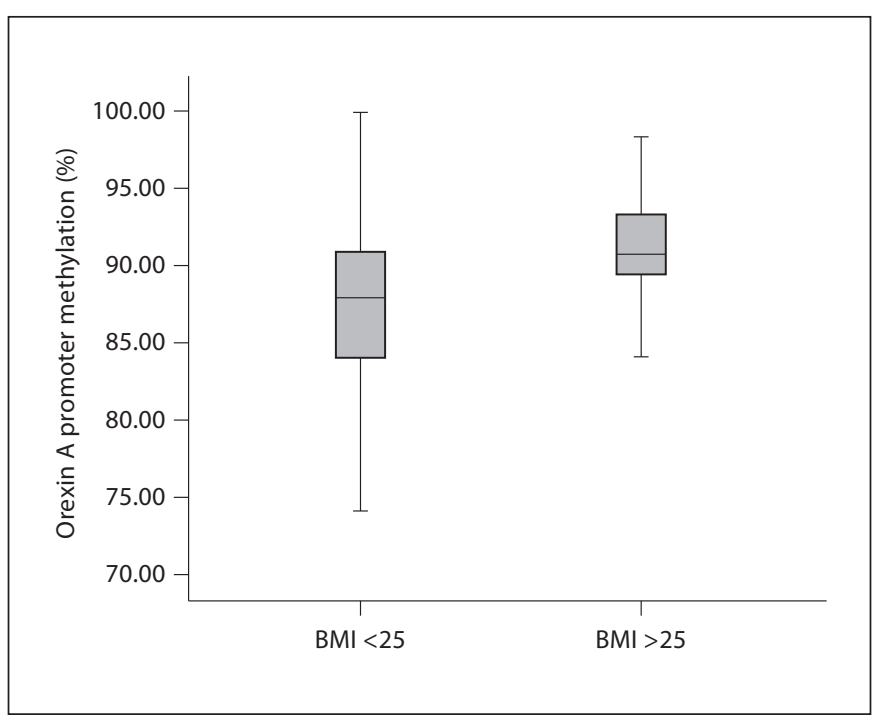

Fig. 4. Orexin A promoter methylation in relation to BMI dichotomized at 25. Promoter methylation differed statistically significantly $(\mathrm{T}=-3.59$, d.f. $=74, \mathrm{p}=0.001)$.

verse agonist of the $\mathrm{CB} 1$ receptor, directly blocks the feeding-relevant endogenous cannabinoid signals through anandamide or 2-arachidonoylglycerol but is also able to block the effects of other unrelated $G$ protein-coupled receptors such as orexin A or B that are localized in hypothalamic nuclei of the same neurons [34-36]. Crespo et al. [12] found behavioral evidence that effective doses of 
a CB1 receptor antagonist are capable of blocking the orexigenic effect of orexin A. Hypothetically, this might lead to downregulation of the orexin system. A similar effect of endocannabinoids on the orexin system has been found in patch-clamp-based research showing that cannabinoids have depressant effects on orexin neurons. These opposing actions could help explain the increase in feeding and reduction in arousal induced by cannabinoids [37]. Results from animal studies have shown that systemic administration of a CB1 receptor antagonist leads to satiety and lower food intake in rats similar to administration of orexin A, supporting the hypothesis that cannabinoid and orexin A systems share a familiar mechanism in the regulation of food intake and that orexigenic circuits are involved in cannabinoid CB1 receptor antagonism-mediated reduction of appetite [12]. It has also been speculated that endocannabinoid and orexin transmission converge in common signalling pathways [15]. As our study subjects with THC dependence demonstrated markedly lower orexin A mRNA expression, it can be hypothesized that exogenously delivered cannabis might operate differently to the endocannabinoid system, which is surely disrupted upon chronic cannabinoid consumption [38].

However, the finding of higher orexin A expression in nonsmokers compared to nicotine-dependent cigarette smokers is in line with other findings of higher plasma orexin A levels in early nicotine withdrawal in comparison to nonsmokers [18]. This result might explain the differences in orexin mRNA expression between smokers and nonsmokers. In this regard, orexin may be a significant regulator of reward and motivation in different kinds of dependencies, in this case comparing cannabis with nicotine dependence [23]. The orexin system seems to be protractedly dysregulated upon alcohol withdrawal [13], similar to nicotine withdrawal in human subjects [18].

Another important aspect of dependence is craving. Addiction can be characterized as a chronic and relapsing disorder accompanied by craving, a state of desire that may lead to relapse and continued substance misuse [39]. Previous studies have found an association between orexin A mRNA levels and craving in both acute and protracted alcohol withdrawal [13]. In this study, craving measured with a visual analogue scale was statistically significantly associated with orexin A mRNA expression. This association was related to misuse of nicotine, alcohol and severity of cannabis misuse measured with the WHO ASSIST scale. Other studies have found an association between orexin plasma levels and craving for cigarettes in early nicotine withdrawal [18]. This study did not assess nicotine craving, as in the study design, only one visit was scheduled and nicotine-dependent participants had not abstained from smoking for more than an hour. The orexin system seems to play a role in various dependencies, such as alcohol, cannabis and nicotine and also amphetamine abuse, leading to immense craving that might be similar to the appetitive drive in response to diminished energy stores [40, 41].

Furthermore, orexin A gene expression was statistically significantly and inversely correlated with satisfaction of life measured with the SWLS. That means that lower orexin expression was associated with less satisfaction with life. This could be explained by the complex interaction of the orexin system, which is downregulated in narcolepsy that is often associated with severe depression. An imbalance between monoaminergic and cholinergic neurotransmission has been proposed as the neurobiological basis of depression as well as narcolepsy. In narcolepsy, this imbalance seems to result from loss of orexins, which might lead to depressive symptoms even in patients without narcolepsy [42]. Furthermore, previous physiological findings in depression show a diminished diurnal variation in cerebrospinal orexin 1 levels. The antidepressant medication sertraline but not bupropion slightly decreased these orexin levels, indicating a serotoninergic influence on the orexin system and a possible involvement in depression [26]. Studies on these relations in rats also showed a suppression of active wake and orexin B caused by the administration of the antidepressant drug clomipramine, hinting at a role of the orexin system in the regulation of sleep and energy homeostasis in depression as well [43]. Unexpectedly, the mean promoter methylation was not statistically related to orexin A gene expression. However, there was a statistically significant difference in promoter methylation with regard to BMI; the higher the orexin A promoter methylation, the higher the BMI. The association between higher body weight and also high BMI levels and high plasma orexin A levels has been well established in several patient groups [44]. In a mixed model with orexin A promoter methylation as the dependent variable, it was only statistically significantly related to the severity of cannabis abuse and the BMI. In sum, the results of the present study hint at a role of the orexin system in cannabis as well as nicotine dependence in comparison to healthy and nonaddicted controls. This is in line with findings in the literature that the orexin system plays a major role in the reinforcing effects of several drugs of abuse such as opioids, nicotine and alcohol; orexins are 
also associated with the neurobiological mechanisms underlying behaviors from relapse to drug-seeking that might be influenced by drug-related environmental stimuli and stress [24].

There are some limitations inherent to this study, as follows. Measuring peripheral orexin mRNA levels as well as promoter methylation does not necessarily reflect the situation in certain brain areas, as methylation and subsequently RNA expression are highly region specific [45]. Nevertheless, precedent studies on orexin A expression in depression as well as during alcohol withdrawal have proposed otherwise $[13,46]$.

Additionally, the products of cannabis act as agonists on the $\mathrm{CB} 1$ and $\mathrm{CB} 2$ receptors [47]. The $\mathrm{CB} 1$ receptor is expressed mainly in the brain, whereas $\mathrm{CB} 2$ is only expressed in peripheral tissues [7] and might interact with peripheral orexin levels as they mainly assert their function presynaptically by influencing neurotransmitter release including dopamine, norepinephrine, glutamate and serotonin [48]. Furthermore, the exact method of application of the drug was not equal in the study population as most subjects with THC dependence used oral as well as inhaled THC. Nevertheless, nicotine-dependent subjects and a sex- and age-matched control group were employed for better evaluation of the results.

The present study managed to assess changes in orexin A expression even with regard to promoter methylation of orexin A in relation to craving, BMI and satisfaction with life, which might possibly be related to brain status, as assumed from similar results from other studies $[13,19,39,46]$. Research on changes within the brain is not always feasible, so that easily accessible markers are required. Orexin A may be a possible candidate to further elucidate mechanisms of weight gain and addiction in THC dependence. Weight gain is also common in nicotine-dependent subjects upon cessation [49]. Hypothetically, orexin might play a role in this frequently observed weight gain as well as in appetite development with THC abuse.

It has previously been speculated that orexin mRNA might pass the blood-brain barrier as the neuropeptide is also able to pass it [50]. As peripherally expressed orexin A mRNA was found to be a potential surrogate marker for brain status, at least in THC-dependent, depressive and alcohol-dependent subjects, methylation status was assessed in peripheral blood as well [46]. However, there was no statistically measurable relation between mRNA expression and promoter methylation measured as a whole. This might be due to the relatively unspecific method or other regulations between expression and methylation that do not necessarily occur directly; orexin A expression may be controlled via the methylation status of other CPG sites than the CPG island of the orexin A promoter region, or, as the method is only able to measure a mean difference over several CPG sites, the effect might have been concealed, or expression might be regulated through mechanisms other than DNA methylation [51].

A manifold association between craving, satisfaction with life, THC as well as nicotine dependence, BMI and orexin A mRNA expression is proposed, hinting at the interplay between cannabinoids, cannabinoid receptors, nicotine and nicotine receptors as well as regulation of appetite and arousal and the orexin system. An orexin antagonist might be a promising candidate to treat THC and even nicotine dependence.

\section{References}

1 Hall W, Degenhardt L: Adverse health effects of non-medical cannabis use. Lancet 2009; 374:1383-1391.

2 Green B, Kavanagh D, Young R: Being stoned: a review of self-reported cannabis effects. Drug Alcohol Rev 2003;22:453-460.

3 Compton WM, Grant BF, Colliver JD, Glantz $\mathrm{MD}$, Stinson FS: Prevalence of marijuana use disorders in the United States: 1991-1992 and 2001-2002. JAMA 2004;291:2114-2121.

4 Haney M: The marijuana withdrawal syndrome: diagnosis and treatment. Curr Psychiatry Rep 2005;7:360-366.
5 Stephens RS, Roffman RA, Curtin L: Comparison of extended versus brief treatments for marijuana use. J Consult Clin Psychol 2000;68:898-908.

6 Dani JA, Balfour DJ: Historical and current perspective on tobacco use and nicotine addiction. Trends Neurosci 2011, E-pub ahead of print.

7 Felder CC, Glass M: Cannabinoid receptors and their endogenous agonists. Annu Rev Pharmacol Toxicol 1998;38:179-200.

8 Howlett AC, Breivogel CS, Childers SR, Deadwyler SA, Hampson RE, Porrino LJ: Cannabinoid physiology and pharmacology: 30 years of progress. Neuropharmacology 2004;47(suppl 1):345-358.
9 Cabral GA, Griffin-Thomas L: Cannabinoids as therapeutic agents for ablating neuroinflammatory disease. Endocr Metab Immune Disord Drug Targets 2008;8:159-172.

10 Gong JP, Onaivi ES, Ishiguro H, Liu QR, Tagliaferro PA, Brusco A, Uhl GR: Cannabinoid CB2 receptors: immunohistochemical localization in rat brain. Brain Res 2006; 1071:10-23.

11 Abel EL: Cannabis: effects on hunger and thirst. Behav Biol 1975;15:255-281.

12 Crespo I, Gomez de Heras R, Rodriguez de Fonseca F, Navarro M: Pretreatment with subeffective doses of Rimonabant attenuates orexigenic actions of orexin A-hypocretin 1. Neuropharmacology 2008;54:219-225. 
13 Bayerlein K, Kraus T, Leinonen I, Pilniok D, Rotter A, Hofner B, Schwitulla J, Sperling W, Kornhuber J, Biermann T: Orexin A expression and promoter methylation in patients with alcohol dependence comparing acute and protracted withdrawal. Alcohol 2011;45: 541-547.

14 Tsujino N, Sakurai T: Orexin/hypocretin: a neuropeptide at the interface of sleep, energy homeostasis, and reward system. Pharmacol Rev 2009;61:162-176.

15 Hilairet S, Bouaboula M, Carriere D, Le Fur G, Casellas P: Hypersensitization of the orexin 1 receptor by the CB1 receptor: evidence for cross-talk blocked by the specific CB1 antagonist, SR141716. J Biol Chem 2003; 278:23731-23737.

16 Nishino S, Ripley B, Overeem S, Lammers GJ, Mignot E: Hypocretin (orexin) deficiency in human narcolepsy. Lancet 2000;355: $39-40$.

17 Sutcliffe JG, de Lecea L: The hypocretins: setting the arousal threshold. Nat Rev Neurosci 2002;3:339-349.

18 von der Goltz C, Koopmann A, Dinter C, Richter A, Rockenbach C, Grosshans M, Nakovics H, Wiedemann K, Mann K, Winterer G, Kiefer F: Orexin and leptin are associated with nicotine craving: a link between smoking, appetite and reward. Psychoneuroendocrinology 2010;35:570-577.

19 Mahler SV, Smith KS, Berridge KC: Endocannabinoid hedonic hotspot for sensory pleasure: anandamide in nucleus accumbens shell enhances 'liking' of a sweet reward. Neuropsychopharmacology 2007;32:22672278.

20 Harkany T, Hartig W, Berghuis P, Dobszay MB, Zilberter Y, Edwards RH, Mackie K, Ernfors P: Complementary distribution of type 1 cannabinoid receptors and vesicular glutamate transporter 3 in basal forebrain suggests input-specific retrograde signalling by cholinergic neurons. Eur J Neurosci 2003; 18:1979-1992.

21 Good CH, Lupica CR: Afferent-specific AMPA receptor subunit composition and regulation of synaptic plasticity in midbrain dopamine neurons by abused drugs. J Neurosci 2010;30:7900-7909.

22 Palmiter RD: Is dopamine a physiologically relevant mediator of feeding behavior? Trends Neurosci 2007;30:375-381.

23 Harris GC, Wimmer M, Aston-Jones G: A role for lateral hypothalamic orexin neurons in reward seeking. Nature 2005;437:556559.

24 Plaza-Zabala A, Flores A, Maldonado R, Berrendero F: Hypocretin/orexin signaling in the hypothalamic paraventricular nucleus is essential for the expression of nicotine withdrawal. Biol Psychiatry 2012;71:214-223.
25 Thornton LK, Baker AL, Lewin TJ, KayLambkin FJ, Kavanagh D, Richmond R, Kelly B, Johnson MP: Reasons for substance use among people with mental disorders. Addict Behav 2012;37:427-434.

26 Agrawal A, Lynskey MT: Candidate genes for cannabis use disorders: findings, challenges and directions. Addiction 2009;104:518532.

27 Henquet C, Di Forti M, Morrison P, Kuepper R, Murray RM: Gene-environment interplay between cannabis and psychosis. Schizophr Bull 2008;34:1111-1121.

28 Ehrlich S, Walton E, Roffman JL, Weiss D, Puls I, Doehler N, Burghardt R, Lehmkuhl U, Hillemacher T, Muschler M, Frieling $\mathrm{H}$ : Smoking, but not malnutrition, influences promoter-specific DNA methylation of the proopiomelanocortin gene in patients with and without anorexia nervosa. Can J Psychiatry 2012;57:168-176.

29 Derogatis LR, Rickels K, Rock AF: The SCL90 and the MMPI: a step in the validation of a new self-report scale. Br J Psychiatry 1976; 128:280-289.

30 Diener E, Emmons RA, Larsen RJ, Griffin S: The Satisfaction With Life Scale. J Pers Assess 1985;49:71-75.

31 WHO ASSIST Working Group: The Alcohol, Smoking and Substance Involvement Screening Test (ASSIST): development, reliability and feasibility. Addiction 2002;97: 1183-1194.

32 Bleich S, Carl M, Bayerlein K, Reulbach U, Biermann T, Hillemacher $\mathrm{T}$, Bonsch $\mathrm{D}$, Kornhuber J: Evidence of increased homocysteine levels in alcoholism: the Franconian alcoholism research studies (FARS). Alcohol Clin Exp Res 2005;29:334-336.

33 Bleich S, Lenz B, Ziegenbein M, Beutler S, Frieling H, Kornhuber J, Bonsch D: Epigenetic DNA hypermethylation of the HERP gene promoter induces down-regulation of its mRNA expression in patients with alcohol dependence. Alcohol Clin Exp Res 2006; 30:587-591.

34 Di Marzo V, Matias I: Endocannabinoid control of food intake and energy balance. Nat Neurosci 2005;8:585-589.

35 Hervieu GJ, Cluderay JE, Harrison DC, Roberts JC, Leslie RA: Gene expression and protein distribution of the orexin-1 receptor in the rat brain and spinal cord. Neuroscience 2001;103:777-797.

36 Valenti M, Cottone E, Martinez R, De Pedro N, Rubio M, Viveros MP, Franzoni MF, Delgado MJ, Di Marzo V: The endocannabinoid system in the brain of Carassius auratus and its possible role in the control of food intake. J Neurochem 2005;95:662-672.

37 Huang H, Acuna-Goycolea C, Li Y, Cheng HM, Obrietan K, van den Pol AN: Cannabinoids excite hypothalamic melanin-concentrating hormone but inhibit hypocretin/ orexin neurons: implications for cannabinoid actions on food intake and cognitive arousal. J Neurosci 2007;27:4870-4881.
38 Fernandez-Espejo E, Viveros MP, Nunez L, Ellenbroek BA, Rodriguez de Fonseca F: Role of cannabis and endocannabinoids in the genesis of schizophrenia. Psychopharmacology (Berl) 2009;206:531-549.

39 Lawrence AJ: Regulation of alcohol-seeking by orexin (hypocretin) neurons. Brain Res 2010;1314:124-129.

40 Kalra SP, Kalra PS: Overlapping and interactive pathways regulating appetite and craving. J Addict Dis 2004;23:5-21.

41 Quarta D, Valerio E, Hutcheson DM, Hedou G, Heidbreder C: The orexin-1 receptor antagonist SB-334867 reduces amphetamineevoked dopamine outflow in the shell of the nucleus accumbens and decreases the expression of amphetamine sensitization. Neurochem Int 2010;56:11-15.

42 Mamelak M: Narcolepsy and depression and the neurobiology of gammahydroxybutyrate. Prog Neurobiol 2009;89:193-219.

43 Thornton LK, Baker AL, Johnson MP, Lewin TJ: Attitudes and perceptions towards substances among people with mental disorders: a systematic review. Acta Psychiatr Scand 2012, E-pub ahead of print.

44 Zhu LY, Summah H, Jiang HN, Qu JM: Plasma orexin-A levels in COPD patients with hypercapnic respiratory failure. Mediators Inflamm 2011;2011:754847.

45 Yagi S, Hirabayashi K, Sato S, Li W, Takahashi Y, Hirakawa T, Wu G, Hattori N, Ohgane J, Tanaka S, Liu XS, Shiota K: DNA methylation profile of tissue-dependent and differentially methylated regions (T-DMRs) in mouse promoter regions demonstrating tissue-specific gene expression. Genome Res 2008;18:1969-1978.

46 Rotter A, Asemann R, Decker A, Kornhuber J, Biermann T: Orexin expression and promoter-methylation in peripheral blood of patients suffering from major depressive disorder. J Affect Disord 2011;131:186-192.

47 Matsuda LA, Lolait SJ, Brownstein MJ, Young AC, Bonner TI: Structure of a cannabinoid receptor and functional expression of the cloned cDNA. Nature 1990;346:561-564.

48 Manzanares J, Uriguen L, Rubio G, Palomo T: Role of endocannabinoid system in mental diseases. Neurotox Res 2004;6:213-224.

49 Kasteridis P, Yen ST: Smoking cessation and body weight: evidence from the Behavioral Risk Factor Surveillance Survey. Health Serv Res 2012, E-pub ahead of print.

50 Kastin AJ, Akerstrom V: Orexin A but not orexin $B$ rapidly enters brain from blood by simple diffusion. J Pharmacol Exp Ther 1999;289:219-223.

51 McGowan PO, Sasaki A, Huang TC, Unterberger A, Suderman M, Ernst C, Meaney MJ, Turecki G, Szyf M: Promoter-wide hypermethylation of the ribosomal RNA gene promoter in the suicide brain. PLoS One 2008; 3:e2085. 